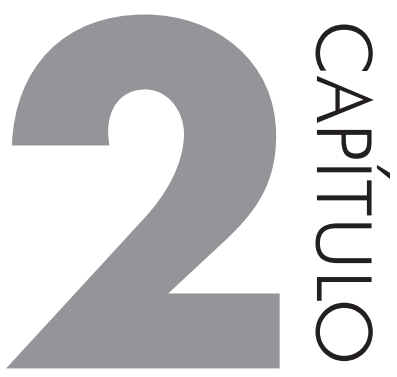

\title{
TUTORIA E O SUJEITO TUTOR NA UNIVERSIDADE ABERTA DO BRASIL mediações, formação e narrativas
}

\section{OTACILIO ANTUNES SANTANA}

\section{HISTÓRICO}

O início do percurso formal para a sistematização desse ensaio foi o convite a participar da Coordenação de Tutoria da Universidade Aberta do Brasil/Universidade Federal de Pernambuco (UAB/UFPE), no qual junto da Coordenação Geral da UAB/UFPE e da Coordenação da Conecte/PROACAD/UFPE, se propôs, para a avaliação do Processo de Tutoria em um semestre letivo, um período de formação e de construção de uma rede de Tutores da UAB/UFPE. Uma formação em que teria múltiplo mediadores (Tutores, coordenadores de curso, coordenador de Tutoria, professores e produtores de materiais didáticos) e uma rede em que os próprios $\mathrm{Tu}$ tores, no engajamento de suas especificidades, poderiam levantar demandas e solucioná-las, na conexão mediada, através de suas vivências, memórias e narrativas.

Esse então foi o objetivo, agora em sequência: i) construir uma rede de Tutores UAB/UFPE; ii) criar um espaço de formação de múltipla-mediação; e iii) avaliar o processo de Tutoria e o sujeito Tutor em formação na potencialização do ensino e aprendizagem no sistema da Universidade Aberta do Brasil, em uma de suas premissas: o impacto social, econômico e ambiental em áreas vulneráveis. 
Pré-definiu-se que se faria um curso de extensão de 120 horas a distância, denominado "e-Tutoria: Zona de Desenvolvimento Proximal Digital", ao longo de um semestre letivo, no qual os objetivos poderiam ser trabalhados virtualmente em um ambiente de aprendizagem (Figura 2.1). O primeiro (março de 2017) e o último (julho de 2017) encontros foram presenciais, o inicial para se planejar e construir um 'contrato didático' em conjunto, e o último, para se consolidar o aprendizado e para apresentação de possíveis caminhos de superação.

Entre esses início e fim, foram programados dez tópicos a serem trabalhados, teoricamente entre os mediadores do curso (téchne) e praticamente entre os Tutores e seus alunos matriculados na UAB/UFPE (práxis). O conteúdo programático dos dez tópicos foram: i) Memorial e Narrativas: Os Mediadores; ii) Zona de Desenvolvimento Proximal (ZDP); iii) Cultura Digital; iv) ZDP e o Ser Conectado: ZDP Digital (ZDPD); v) Saberes Necessários na ZDPD; vi) ZDPD, criatividade e inovação; vii) Big Data e Circuito Tautológico: Produção e Reprodução; viii) Autoria para o Simpósio; ix) Auto-Avaliação e Avaliação; e x) Quo vadis! Cada tópico tinha quatro partes: i) teórica (textos e vídeo-aulas); ii) a de interação (fóruns e chats); iii) uma de atividade de aplicação de conteúdo pelo tutor em suas turmas na UAB; e iv) uma de avaliação (auto-avaliação, da atividade e das interações).

A rede de contatos foi construída pelos Tutores dos Cursos de Graduação a distância da UFPE (Licenciatura em Geografia, Letras Português, Letras Espanhol, Matemática e do Bacharelado em Ciências Contábeis), e todos os mediadores supracitados, de todos os Pólos no qual foram oferecidos esses cursos: Afrânio, Carpina, Garanhuns, Ipojuca, Jaboatão, Limoeiro, Olinda, Palmares, Pesqueira, Petrolina, Recife, Salgueiro, Santa Cruz, Surubim, Tabira, e Trindade, em Pernambuco; e em Maragogi em Alagoas.

Ao final, uma avaliação integrativa do processo de Tutoria foi sintetizada, a partir da auto-avaliação do Tutor frente a sua atuação na UAB, da participação do curso proposto e da relação com a avaliação dele pelos seus alunos UAB, avaliado pelo coordenador do Curso, pela coordenação de Tutoria, e pelos professores em que os Tutores suplementam e complementam (LIMA et al., 2017).

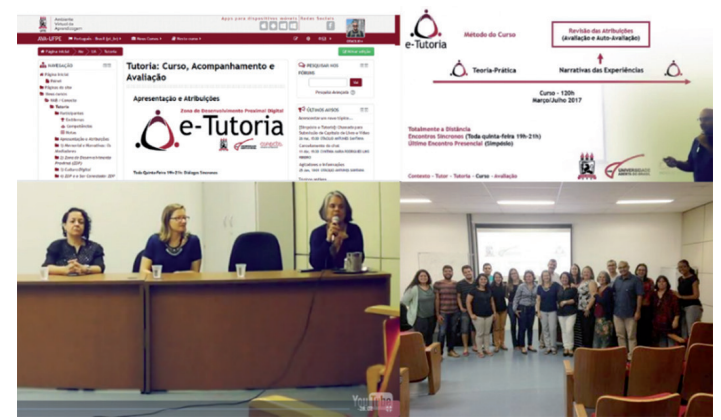

Figura 2.1. Sala de Aula Virtual (AVA-UFPE), apresentação do formato, mesa de abertura do Curso "e-Tutoria: Zona de Desenvolvimento Proximal Digital" e Tutores. 


\section{MÉTODOS E ANÁLISES}

A sintetização do percurso da rede, do espaço de formação e da avaliação, ao seu final, seguiu o método e a análise da Educometria, que a partir dos dados quantitativos há uma descrição baseada em uma narrativa qualitativa documentada (SANTANA, O. A, 2016a; SANTANA, 2016b; SANTANA, 2016c; SANTANA; PETROVA, 2016; SANTANA, 2015a; SANTANA, 2015b; SANTANA et al., 2015; SANTANA, 2014a; SANTANA, 2014b; SANTANA et al., 2013; SANTANA, 2013; SANTANA, 2011; SANTANA, et al., 2011; SANTANA; PEIXOTO, 2010). A sequência da apresentação dos dados se deu da seguinte forma: i) o formato e avaliação da mediação dos Tutores frente aos alunos da UAB; ii) Tutoria e resultado institucional; iii) a formação e avaliação dos Tutores; e iv) o aluno UAB e autonomia no percurso.

Participaram da pesquisa, tanto em respostas quanto pelo acompanhamento das atividades, 87 alunos da UAB de um universo de 416 matriculados (até julho de 2017), 31 Tutores (21 Tutores a distância e 10 Tutores presenciais); 4 coordenadores de curso; e um coordenador de Tutoria. Dos Tutores, cinco a distância do Curso de Ciências Contábeis; dois a distância e dois presenciais do Curso de Geografia; nove a distância do curso de Letras Espanhol; cinco a distância e dois presenciais do Curso de Letras Português; e seis presenciais do Curso de Matemática.

Os dados, as informações e as avaliações sobre os Tutores, os alunos e os coordenadores foram coletados através dos relatórios de acessos do Ambiente Virtual de Aprendizagem (AVA-Moodle -UFPE), dos questionários estruturados (Likert, 1932) e abertos, dos dados obtidos no Sistema de Informações e Gestão Acadêmica (SIG@) (e.g. notas). As análises quantitativas e gráfica através do programa SigmaPlot 13 (Systat Software, Inc, Sao Jose, EUA) e as análises e sínteses qualitativas pela formação de nuvens de palavras (SANTANA, 2016a) e pela análise de conteúdo: démarches das narrativas (BILLOUET, 2007) (Figura 2.2).

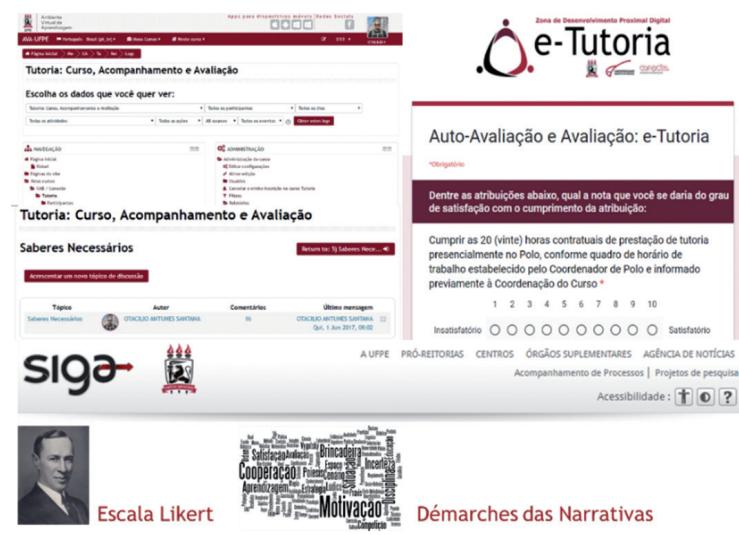

Figura 2.2. Ferramentas Virtuais utilizadas para coleta dos dados: Ambiente Virtual de Aprendizagem (AVA-Moodle-UFPE), Sistema de Informações e Gestão Acadêmica (SIG@), Formulários (Google Drive), e Wordle (Nuvens de Palavras). 
Para avaliação dos Tutores, atribuições foram designadas a eles antes de sua contratação, e foi o parâmetro para compreender como a relação entre o cumprimento com louvor das atribuições do tutor poderiam potencializar o aprendizado do aluno UAB/UFPE. As atribuições estão elencadas na Tabela 2.1.

Tabela 2.1. Atribuições dos Tutores a distância e Tutores presenciais da Universidade Aberta do Brasil/Universidade Federal de Pernambuco (UAB/UFPE).

\begin{tabular}{|l|l|}
\hline \multicolumn{1}{|c|}{ TUTORES A DISTÂNCIA } & \multicolumn{1}{|c|}{ TUTORES PRESENCIAIS } \\
\hline $\begin{array}{l}\text { A) Dedicar, no mínimo, 2 (duas) horas } \\
\text { diárias, de segunda-feira a sexta-feira, às } \\
\text { atividades virtuais utilizando os recursos } \\
\text { tecnológicos disponibilizados para intera- } \\
\text { gir com os estudantes, esclarecendo dúvi- } \\
\text { das em relação ao conteúdo e incentivan- } \\
\text { do os estudantes ao trabalho cooperativo, } \\
\text { ais de prestação de tutoria presencialmen- } \\
\text { telaborativo e em grupo, mediando e ava- } \\
\text { de trabalho estabelecido pelo Coordena- } \\
\text { diando as atividades discentes }\end{array}$ & Coordenação do Curso \\
\hline $\begin{array}{l}\text { B) Dedicar 2 (duas) horas semanais à à } \\
\text { atividade chat para o atendimento dos } \\
\text { estudantes }\end{array}$ & $\begin{array}{l}\text { B) Estar atento e zelar pelo cumprimento } \\
\text { do calendário acadêmico e da organiza- } \\
\text { ção acadêmica }\end{array}$ \\
\hline $\begin{array}{l}\text { C) Manter regularidade de acesso ao AVA } \\
\text { e dar retorno às solicitações dos cursistas } \\
\text { no prazo máximo de 24 horas }\end{array}$ & $\begin{array}{l}\text { C) Auxiliar o coordenador de polo nas } \\
\text { atividades administrativas relacionadas às } \\
\text { atividades didático-pedagógicas }\end{array}$ \\
\hline $\begin{array}{l}\text { D) Acompanhar as atividades discentes, } \\
\text { conforme o calendário acadêmico do curso }\end{array}$ & $\begin{array}{l}\text { D) Auxiliar o professor do componente cur- } \\
\text { ricular e/ou tutor a distância no desenvolvi- } \\
\text { mento das atividades didático-pedagógicas } \\
\text { realizados durante os encontros presenciais }\end{array}$ \\
\hline $\begin{array}{l}\text { E) Auxiliar o professor do componente } \\
\text { curricular na organização, elaboração e } \\
\text { construção das atividades na sala virtual }\end{array}$ & $\begin{array}{l}\text { E) Participar dos encontros presenciais pro- } \\
\text { gramadas para o período letivo de todas as } \\
\text { disciplinas, conforme calendário escolar }\end{array}$ \\
\hline $\begin{array}{l}\text { F) Apoiar o professor do componente cur- } \\
\text { ricular no desenvolvimento das atividades } \\
\text { docentes }\end{array}$ & $\begin{array}{l}\text { F) Consultar a sala virtual de todas as dis- } \\
\text { ciplinas para o acesso ao plano de aula, } \\
\text { visando acompanhar e orientar os estu- } \\
\text { dantes no desenvolvimento pedagógico } \\
\text { das disciplinas e dos conteúdos que estão } \\
\text { sendo ministrados }\end{array}$ \\
\hline
\end{tabular}




G) Estabelecer contato permanente com
os alunos e mediar às atividades discentes
H) Colaborar com a coordenação do cur-
so e o com professor na avaliação dos es-
tudantes

I) Participar das atividades de capacitação e atualização promovidas pelo UFPE

J) Elaborar e encaminhar ao professor do componente curricular relatórios semanais de acompanhamento dos alunos

K) Elaborar e encaminhar relatório técnico sobre o desenvolvimento de suas atividades e o impacto causado no aprendizado dos estudantes

L) Elaborar e encaminhar à coordenação do curso relatórios de realização dos encontros presenciais com as atas de presença dos alunos

M) Elaborar e encaminhar à coordenação do curso, no prazo de 2 (dois) dias úteis após a realização da atividade, a prestação de contas quando da disponibilização de ajuda de custo para realização dos encontros presenciais

N) Participar do processo de avaliação do componente curricular sob orientação do professor responsável pelo componente curricular

O) Participar dos encontros presenciais (aulas e outras atividades) previstos no calendário do componente curricular
G) Interagir com os estudantes, esclarecendo dúvidas em relação ao uso das tecnologias e mídias utilizadas para o desenvolvimento das atividades pedagógicas (material impresso, vídeos, animações, dentre outros)

H) Manter regularidade de acesso ao AVA e dar retorno às solicitações do cursista no prazo máximo de 24 horas

I) Elaborar relatórios mensais de acompanhamento dos alunos e encaminhar à coordenação de tutoria

J) Participar do processo de avaliação da disciplina sob orientação do professor responsável

K) Apoiar operacionalmente a coordenação do curso nas atividades presenciais nos polos, em especial na aplicação de avaliações

L) Estabelecer com os estudantes horários de estudos em grupos, orientá-los e acompanhá-los na realização desses estudos, incentivando-os à realização de trabalhos acadêmicos de forma cooperativa, colaborativa e em grupo

M) Orientar, supervisionar e controlar o uso dos equipamentos eletrônicos do polo

N) Proporcionar aos alunos, por meio da utilização de ferramentas, meios e métodos de busca de materiais didáticos complementares para a efetivação e o aprofundamento de temas abordados no decorrer do Curso

O) Incentivar e alertar os alunos da necessidade de postar atividades dentro do prazo estabelecido pelo Professor responsável pelo componente curricular 


\begin{tabular}{|c|c|}
\hline $\begin{array}{l}\text { P) Apoiar, operacionalmente, o professor } \\
\text { responsável pelo componente curricular } \\
\text { e a coordenação do curso nas atividades } \\
\text { presenciais nos polos de apoio presencial, } \\
\text { em especial, na aplicação de avaliações }\end{array}$ & $\begin{array}{l}\text { P) Participar de reuniões e capacitações } \\
\text { agendadas pela Coordenação de Polo ou } \\
\text { de Tutoria }\end{array}$ \\
\hline \multirow[t]{5}{*}{$\begin{array}{l}\text { Q) Responder a auto-avaliação semestral- } \\
\text { mente }\end{array}$} & $\begin{array}{l}\text { Q) Orientar os estudantes na indicação } \\
\text { de livros, periódicos, artigos, dissertações, } \\
\text { teses, dentre outros, que possam auxiliá- } \\
\text {-los no desenvolvimento de suas ativida- } \\
\text { des acadêmicas }\end{array}$ \\
\hline & $\begin{array}{l}\text { R) Entregar Relatório de Atividades se- } \\
\text { mestralmente e a Ficha de Acompanha- } \\
\text { mento de alunos ao Coordenador de Polo } \\
\text { informando as atividades realizadas no se- } \\
\text { mestre anterior, as dificuldades encontra- } \\
\text { das para o desenvolvimento da função, as } \\
\text { sugestões para melhoria do curso e da sua } \\
\text { função, as dificuldades encontradas pe- } \\
\text { los estudantes, relação de alunos que não } \\
\text { participaram dos encontros presenciais e } \\
\text { os motivos que levaram os estudantes a } \\
\text { não comparecerem aos encontros, infor- } \\
\text { mação dos contatos estabelecidos com os } \\
\text { estudantes que estão há } 3 \text { (três) dias ou } \\
\text { mais sem acessar o ambiente virtual, den- } \\
\text { tre outros }\end{array}$ \\
\hline & $\begin{array}{l}\text { S) Encaminhar para a Coordenação do } \\
\text { Curso os requerimentos de cancelamento } \\
\text { de matrícula, aproveitamento de disci- } \\
\text { plina, trancamento de curso, revisão de } \\
\text { questões, notas/avaliações, licença espe- } \\
\text { cial, tratamento excepcional entre outros } \\
\text { requerimentos que se fizerem necessários }\end{array}$ \\
\hline & $\begin{array}{l}\text { T) Ter disponibilidade para atendimento } \\
\text { aos estudantes no ambiente virtual à dis- } \\
\text { tância e nos encontros presenciais nos po- } \\
\text { los de apoio presencial }\end{array}$ \\
\hline & $\begin{array}{l}\text { U) Responder a auto-avaliação semestral- } \\
\text { mente }\end{array}$ \\
\hline
\end{tabular}


Ao final do percurso, os Tutores narraram suas vivências (Figura 2.3), processo fundamental para a compreensão das inferências e evidências sensíveis (poiesis), que não se pôde mensurar e classificar com os dados quantitativos e qualitativos. Essas narrativas foram registradas em vídeos e apresentadas na Parte II desse livro.

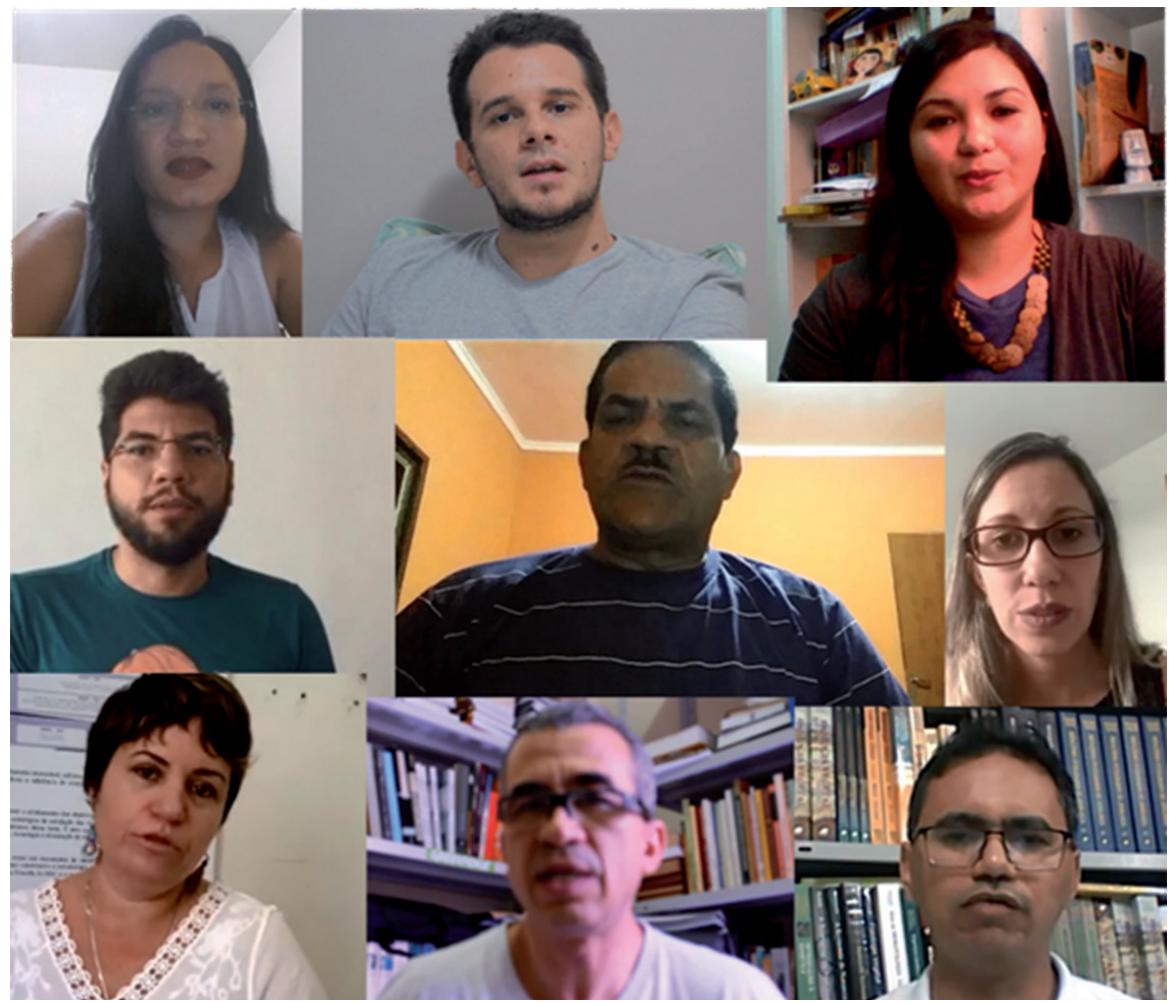

Figura 2.3. Tutores a narrar suas vivências e memórias.

\section{FORMATO E AVALIAÇÃO DA MEDIAÇÃO DOS TUTORES FRENTE AOS ALUNOS DA UAB/UFPE}

A mediação entre os Tutores e alunos foram em sua maior parte a distância, como requerido pela modalidade $\mathrm{EaD}$, porém $13 \%$ do contato se deu de modo presencial, principalmente em grupos de estudos (Figura 2.4A). Os tutores, em média, acessavam mais do que os alunos por horas por semana na sala virtual no AVA-UFPE, $27 \pm 3 \mathrm{~h} \mathrm{semana}^{-1}$ e $14 \pm 1 \mathrm{~h}^{\text {semana }}{ }^{-1}$, respectivamente (Figura 2.4B). Virtualmente, um dado que se destacou, é que em porcentagem no tempo, apenas $32 \%$ da relação tutor-aluno foi pelo AVA-UFPE, $68 \%$ foi em outro ambiente ou rede social: Facebook, Whatsapp, Youtube, Skype, Telegram, Software de Cálculos, etc... (Figura 2.4C). 

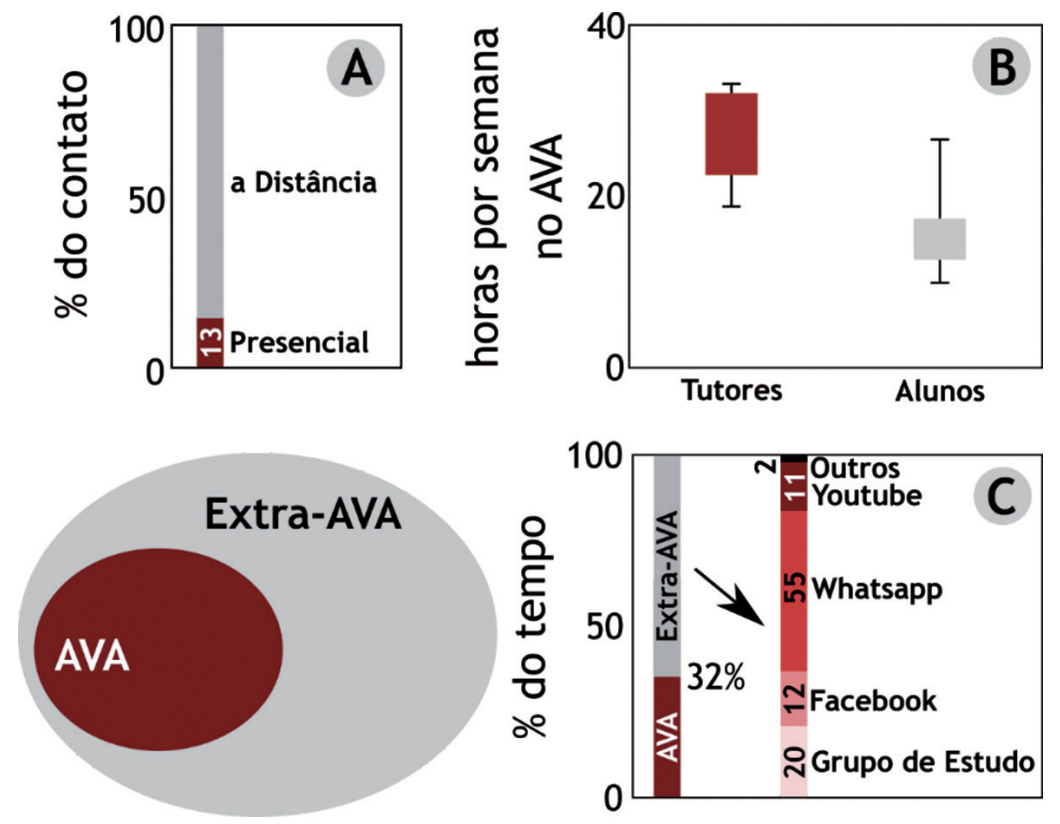

Figura 2.4. (A) Porcentagem de Contato do Tutor com Aluno UAB; (B) Horas por semana no Ambiente Virtual de Aprendizagem (AVA-UFPE); (C) Porcentagem do tempo no AVA e Extra-AVA ( $n=31$ tutores).

Cada curso mostrou uma certa tendência em utilizar seu tempo no processo de ensino e aprendizagem em ferramentas Extra-AVA (Figura 2.5), como foi o caso do Curso de Matemática que utilizavam ambiente de desenvolvimento integrado para cálculos estatísticos e gráficos, por exemplo, ou o Whatsapp para resolução de cálculos simultaneamente em grupos de estudo. O Curso de Geografia e Letras Português utilizavam como recurso principal as vídeos-aulas e webconferências. A especificidade do conteúdo de cada Curso fez com que cada processo de ensino e aprendizagem fosse instrumentalizado com ferramentas específicas dentro e fora do AVA.

O cumprimento das atribuições dos Tutores foi certificado pelos pesos médios dados na avaliação preenchidas pelos próprios Tutores (auto-avaliação); pelos alunos; pelos coordenadores de curso; e pelo coordenador de Tutoria. Tanto os Tutores a distância (Figura 2.6A) e os Tutores presenciais (Figura 2.6B), receberam em média notas superiores a oito na escala Likert (de 0 a 10), apesar que em algumas atribuições, por algum motivo, os alunos atribuíram pesos inferiores a sete, por exemplo, para os Tutores a distância nos itens: A), G) e O); e para os Tutores presenciais nos itens: G), L) e T) (letras referentes a Tabela 2.1), todos justificados pela baixa motivação da turma quando requerida a construção conjunta de uma atividade. 


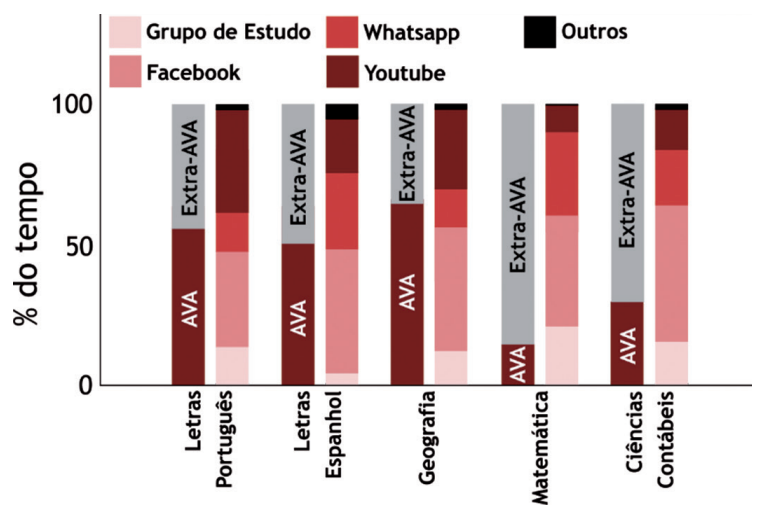

Figura 2.5. Porcentagem do tempo no AVA-UFPE e Extra-AVA-UFPE utilizado pelos alunos para o cumprimento das atividades específicas de cada Curso ( $n=31$ tutores).

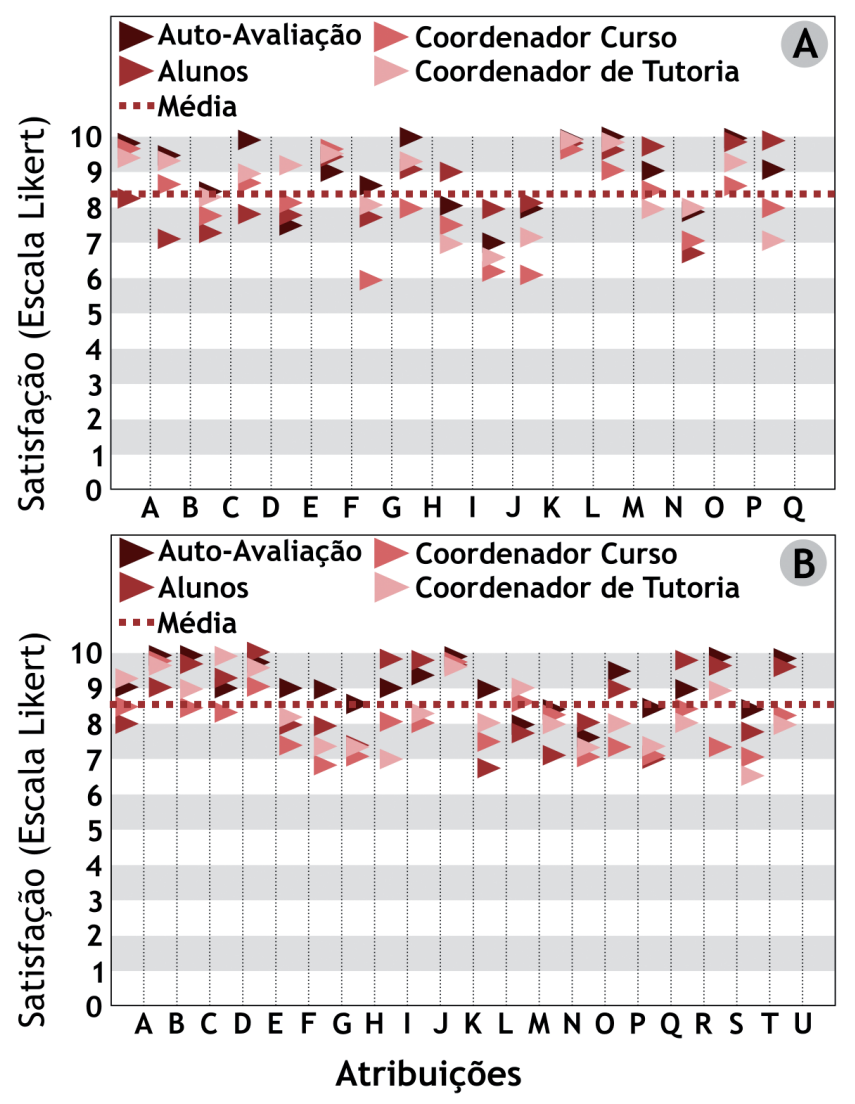

Figura 2.6. Satisfação em Escala Likert do comprimento das atribuições dos Tutores a distância (A) e presenciais (B), avaliados pelos alunos UAB, coordenadores de curso, coordenador de Tutoria e de sua auto-avaliação (Tutores $n=31,21$ a distância + 10 presencial; Alunos UAB $n=87$ / 416; Coordenadores de Curso $n=4$; e Coordenador de Tutoria $n=1$ ). Letras de A a Q (6A) e de A a U (6B) ver Tabela 2.1. 


\section{TUTORIA E O RESULTADO INSTITUCIONAL}

É senso comum que a presença do Tutor ativamente no processo de ensino e aprendizagem é fundamental (ver SANTANA et al., 2011). A corroborar com essa afirmação nas turmas Tutoradas, que representaram $89 \%$ das disciplinas dos Cursos EaD da UAB/UFPE, os alunos, em média, tiraram notas finais mais altas (Figura 2.7) e acessaram mais o AVA-UFPE (n de logs/turma). Também se pôde observar uma proporcionalidade direta e significativa entre o número de acesso ao AVA e o resultado da nota final na disciplina.

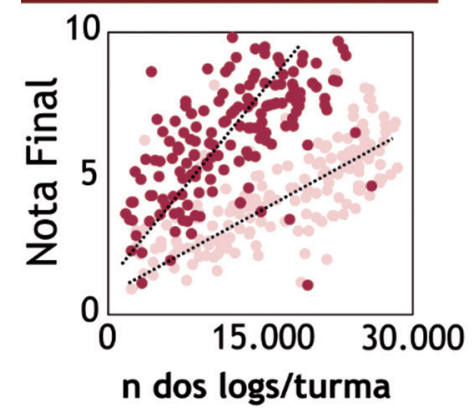

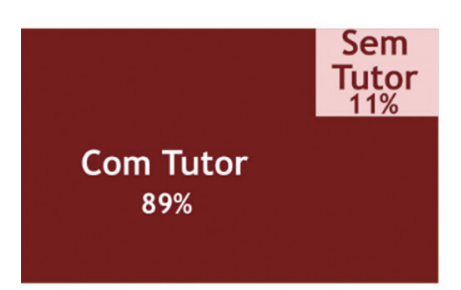

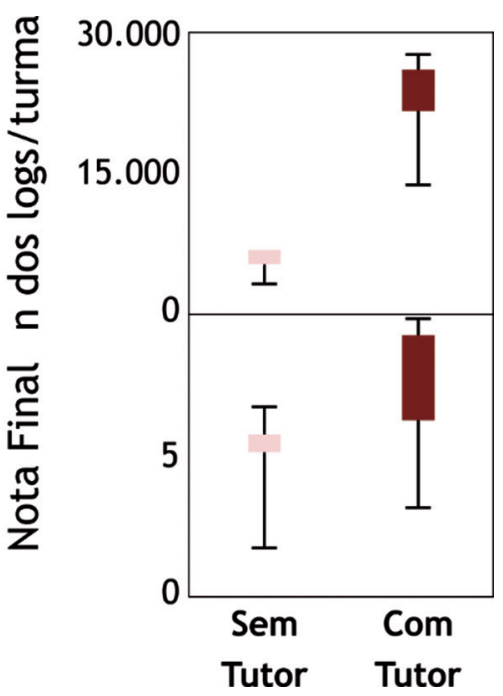

Figura 2.7. Porcentagem das disciplinas com e sem tutores, e notas dos alunos UAB em relação ao número de logs do Tutor na sala virtual no AVA-UFPE (n = 207 componentes curriculares).

Porém, nos trabalhos produzidos sobre Tutoria, o Tutor é o principal e único fator no resultado do Processo de Tutoria, ou seja, é atribuído a si os gargalos do processo. E essa consideração se faz sem um estudo da formação continuada e da narrativa do sujeito Tutor. Não se leva em consideração também, o contexto institucional (PADILHA; ZABALZA, 2016) em que o Tutor está inserido. Não se pode então, confundir Tutor e Processo de Tutoria em um mesmo espectro no resultado institucional. Como foi selecionado o Tutor? Como está sendo a formação continuada dele? Quais os incentivos e fomentos em que o Tutor é inserido institucionalmente? Quais os valores capitais que o Tutor receberá pós-tutoria em sua futura e possível admissão e absorção no mercado de trabalho? Essas e outras questões deverão ser formuladas no momento da avaliação do Processo de Tutoria. Por isso, é basilar nesse capítulo esse parêntese: o espaço de formação construído foi para o sujeito Tutor e a avaliação se cai sobre o Processo de Tutoria em 
que a instituição e todas as variáveis não controladas (condições dos Polos, rede wifi institucional, feedback administrativo, valorização institucional, etc...) estão inseridas nos erros e nos acertos do processo (Figura 2.8).

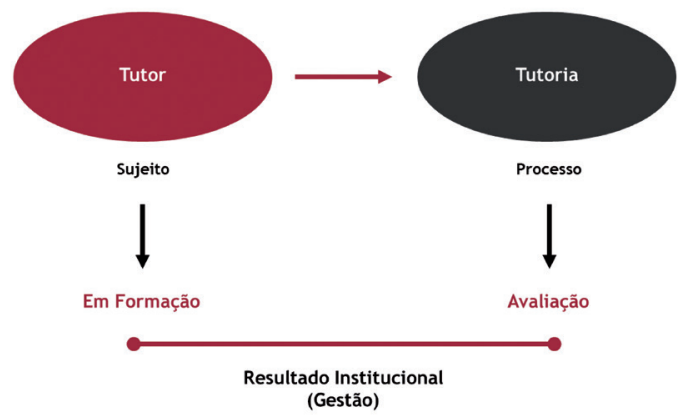

Figura 2.8. Esquema de como deve ser direcionada a síntese do Resultado Institucional na avaliação do Tutor e do Processo de Tutoria.

\section{FORMAÇÃO E AVALIAÇÃO DOS TUTORES}

O curso de extensão "e-Tutoria: Zona de Desenvolvimento Proximal Digital", que foi o espaço de formação multi-mediada, teve a conclusão de $67 \%$ dos Tutores inscritos que exaltaram como pontos positivos, principalmente, a rede de contatos formada e as novas estratégias de ensino e aprendizagem consolidadas. Os que evadiram do curso de formação destacaram o acúmulo de atividades ('falta de tempo') e por isso não puderam dar continuidade na formação (Figura 2.9). Outro dado de destaque foi que os tutores evadidos do curso descreveram que o método de construção do conhecimento foi desestimulador, ou seja, alguns Tutores em cursos EaD não investem na sua formação em cursos na modalidade $\mathrm{EaD}$, um paradoxo.

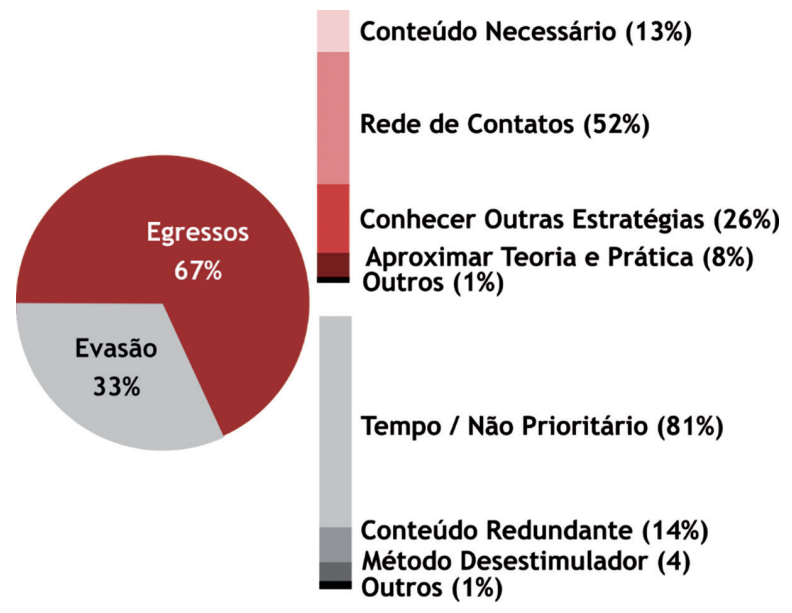

Figura 2.9. Porcentagem dos egressos e dos evadidos no Curso e os principais motivos citados para tal $(n=31)$. 
Os Tutores ao longo dos tópicos do curso mostraram um comportamento rumo a autonomia, comportamento estimulado pelo design instrucional do curso, ou seja, no início com uma prioridade para cargas teóricas, estudo de conceitos estabelecidos, e de forma individualizada, e a partir de um certo ponto a priorizar a sistematização e criação de novos conceitos de forma coletiva. Se destaca as interações assíncronas, ao final, justamente pela construção coletiva no qual cada mediador, em seu momento e espaço, adicionava uma peça ao quebra cabeça do conhecimento e da aprendizagem (Figura 2.10).

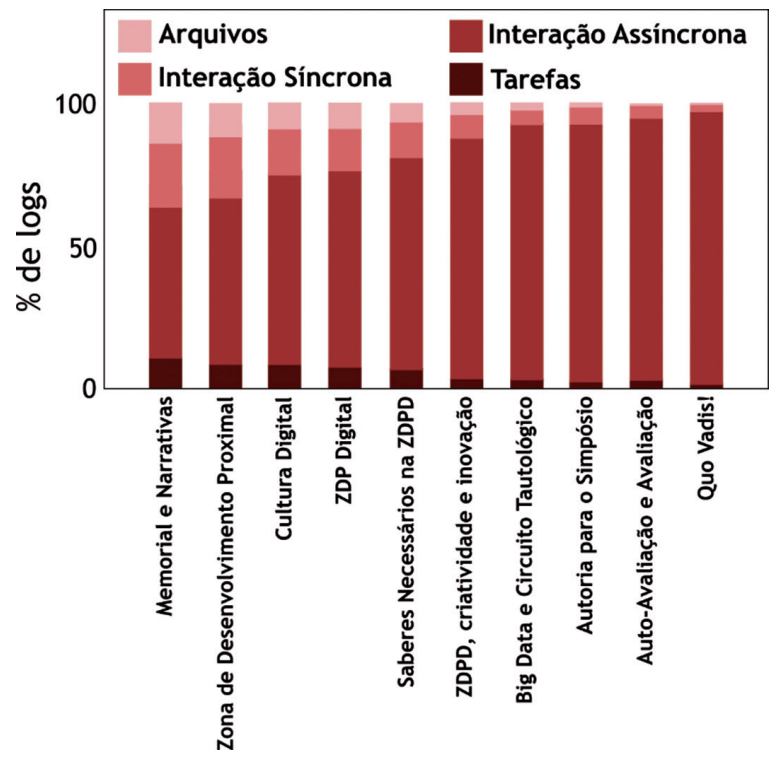

Figura 2.10. Porcentagem de acessos (logs) dos alunos nas atividades e nos materiais ao longo dos tópicos estudados.

Os Tutores avaliaram o espaço de formação com o curso de extensão. Em média, eles indicaram que foi satisfatório, pois construiu uma rede produtiva de interação e mediação de demandas e caminhos para solução, avaliando ao final como excelente (Figura 2.11). Na avaliação final desse também espaço de mediação, os Tutores, em sua maioria, requisitaram outros espaços com outras temáticas.

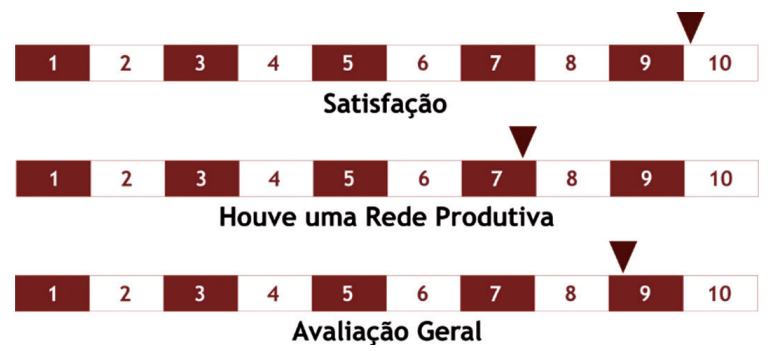

Figura 2.11. Avaliação Geral apresentada em média pelos Tutores que participaram do Curso ( $n=31$ tutores). 


\section{ALUNOS UAB E A AUTONOMIA NO PERCURSO}

Os Tutores também avaliaram os alunos quanto a motivação (se os alunos superavam o mínimo exigido para o cumprimentos das disciplinas do curso de graduação), quanto a disciplina (se os alunos construíam seus métodos de aprendizagem e os executavam em suas rotinas) e quanto a autonomia (quando os alunos construíam suas ementas para cada disciplina, a perpassar a ementa dada pela matriz curricular, e começa a partir disso a hipotetizar e a sistematizar relações interdisciplinares dos conteúdos ementares). Baixa automotivação, baixa autodisciplina e baixa autonomia esse é o cenário em que o tutor encontra a maioria dos alunos UAB/UFPE (Figura 2.12). Esse dado é geral, na maioria dos Polos da UAB pelo Brasil.

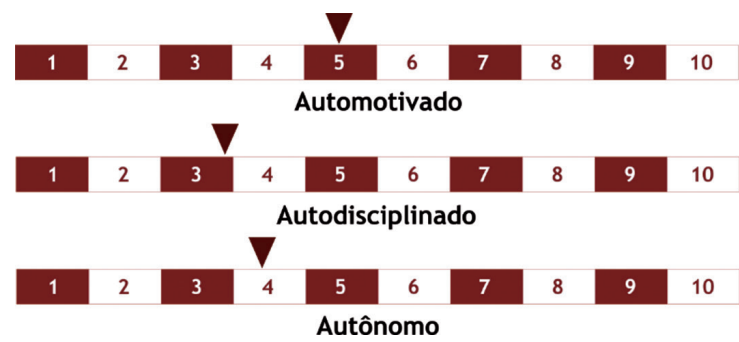

Figura 2.12. Avaliação Geral apresentada em média pelos Tutores sobre a motivação, disciplina e autonomia dos Alunos UAB/UFPE ( $\mathrm{n}=31$ tutores).

O público-alvo para $\mathrm{EaD}$, em sua concepção, seria o aluno que tivesse um alto grau de automotivação, autodisciplina e autonomia. Nos sistemas educacionais que buscam esse tipo de aluno, não se preocupam, por exemplo, com dados de evasão. Se o aluno não é automotivado, autodisciplinado e autônomo ele não está preparado para sua formação a nível superior na modalidade EaD. No Brasil, o EaD a nível superior, veio para atingir um público alvo nas regiões metropolitanas que em sua maioria não pôde estudar regularmente (e.g. por se ocuparem integralmente com trabalho), ou um público-alvo que reside em regiões longe das metrópoles em que as universidades e o sistema de ensino superior não se estabeleceram (e.g. Sertão). Esse público-alvo que ingressa no sistema da UAB necessita, em sua maioria, de um acompanhamento motivacional e disciplinar pela falta no simbolismo concreto que se têm do imaginário educacional: 'o professor em uma sala de aula cheia de carteira com alunos a folhear livros', e essa é a avaliação dos Tutores sobre os alunos (Figura 2.13). 


\begin{tabular}{|c|c|}
\hline Automotivado & Heteromotivado \\
\hline Autodisciplinado & Heterodisciplinado \\
\hline Autonômo & Heterônomo \\
\hline Ideal & Real \\
\hline
\end{tabular}

Figura 2.13. Escala entre autonomia e heteronomia e posição aluno UAB/UFPE, segundo a avaliação dos Tutores.

Qual então seria a motivação dos alunos ao entrarem nos Cursos de Graduação da UAB? A maioria respondeu que foi pela competência que queria ter pós-formatura, ou seja, pela diplomação e possível absorção no mercado (Figura 2.14A). Poucos entraram pela vocação, pelo exemplo ou pela cooperação e competição. E isso influi na motivação, "faço uma coisa que não gosto, mas que é funcional”, relata um aluno UAB/UFPE. Os alunos já a cursar os cursos a distância procuraram os Tutores, em sua maioria (Figura 2.14B), para solucionar um 'problema' (conhecimento como produto) e não para superar algum obstáculo que o faria construir o conhecimento (meta-ciência ou conhecimento como processo). Outro destaque aqui, e que o sistema de gerenciamento do AVA permite, é a certificação de que o aluno só busca acessa ( $n$ de logs) a sala virtual nas vésperas das atividades avaliativas (Figura 2.15), o que ressalta o anteriormente relatado sobre a heteronomia (motivação extrínseca).

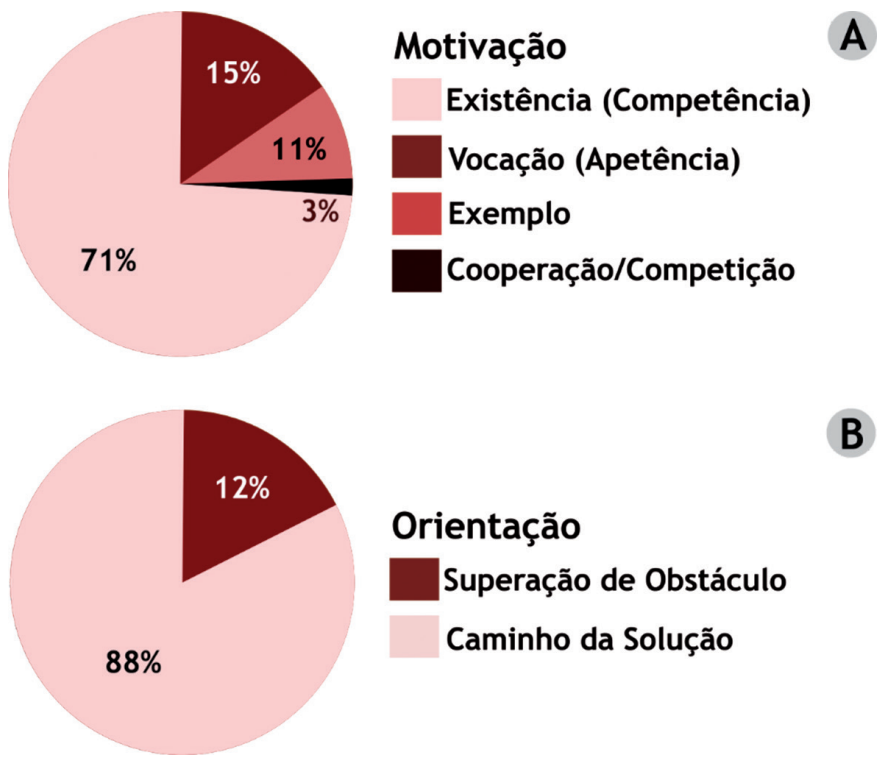

Figura 2.14. Porcentagem do motivo da ação dos alunos UAB/UFPE (A) e qual sentido da busca de orientação ao Tutor por esse aluno (B) ( $n=87$ alunos UAB). 


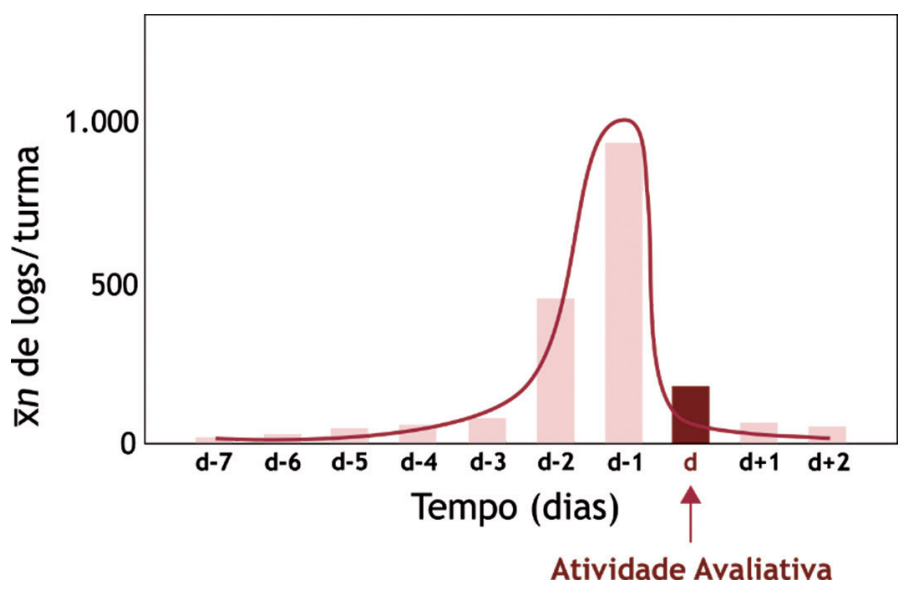

Figura 2.15. Frequência média de logs por turma em dias de atividades avaliativas para os alunos UAB/UFPE em seus cursos de graduação. ( $d$ = dia)

Nesse contexto, se percebe a diferença entre os Tutores que residem e atuam nos polos situados na região metropolitana e nos polos do interior. $\mathrm{Na}$ região metropolitana a relação Tutor-aluno tem um caráter impessoal, de toda a comunicação e interação está centrada no processo de ensino e aprendizagem per si. Nos polos do interior, a relação Tutor-aluno perpassa o contexto educacional e flui para uma convivência que as vezes potencializa o aprendizado e que ao mesmo tempo pode fortalecer a heteronomia do aluno (Figura 2.16).

$\begin{array}{ccc}\text { Impessoalidade } & \text { Tutor } & \text { Pessoalidade } \\ \begin{array}{c}\text { Polos da Região } \\ \text { Metropolitana }\end{array} & \begin{array}{c}\text { Polos do } \\ \text { Interior }\end{array}\end{array}$

Figura 2.16. Escala entre pessoalidade e impessoalidade do aluno UAB advindos dos Polos Metropolitanos e dos Polos do Interior do Estado de Pernambuco.

\section{LIMITAÇÕES}

Nesse percurso, algumas limitações foram apontadas pelo Tutor e pela coordenação de Tutoria. Os Tutores ainda buscam um reconhecimento concreto legal ("se é valorizado dentro do gueto da $\mathrm{EaD}$, mas fora..."), uma valorização política curricular (e.g. aparecer uma pontuação diferenciada em editais de concursos públicos), e pela autonomia limitada na construção das atividades, conteúdos e construção de objetos educacionais nas disciplinas. Os Tutores ainda relataram que os alunos UAB/UFPE não possuem um entendimento sobre a distinção de informação e formação, e que utilizam as tecnologias digitais de informação e 
comunicação como ferramentas de trocas de informação e pouco como formação. E nesse imbróglio, a variável 'tempo' é sempre requisitada: 'quero uma resposta elaborada instantaneamente', a elevar o Tutor a um ser onipresente ("tem que estar lá quando preciso”).

A coordenação de Tutoria destaca que as limitações de não haver uma forte relação entre Tutor-coordenação de Tutoria se dá pela principalmente pela quantidade de polos, pela falta de um constante feedback por parte dos coordenadores de curso, e as vezes uma centralização das informações, por uma falta de compromisso com a formação continuada e a construção de espaços mediados, e por uma carência na pesquisa holística e perene do processo de Tutoria.

\section{CONSIDERAÇÕES FINAIS}

A Coordenação de Tutoria UAB/UFPE nos meses de outubro de 2016 a julho de 2017 conseguiu cumprir todos os objetivos propostos de construir uma rede de Tutores UAB/UFPE; de criar um espaço de formação de múltipla-mediação; e de avaliar o processo de Tutoria e o sujeito Tutor em formação na potencialização do ensino e aprendizagem no sistema da Universidade Aberta do Brasil, em uma de suas premissas: o impacto social, econômico e ambiental em áreas vulneráveis (esses impactos serão descritos no capítulo 14).

Além disso, se pôde concluir com os dados e as análises apresentadas em todo esse livro: i) que houve um início de um Sistema de Avaliação Educométrico para o Processo de Tutoria (carente na literatura); ii) que o tempo de contato Tutor-aluno Extra-AVA sobrepõe o registrado em AVA; iii) que as especificidades dos cursos avaliados se ressaltam com as atividades no AVA e Extra-AVA; iv) que as atribuições estabelecidas para o Tutores foram cumpridas de forma eficiente e certificadas pela auto-avaliação, pela avaliação dos coordenadores, pela avaliação dos alunos e pela coordenação de Tutoria; v) que existe uma correlação direta e significativa entre a presença do Tutor e a quantidade e qualidade de acesso e resultado na avaliação dos alunos UAB; vi) que na formação, os egressos do curso de formação (Tutores) destacaram a rede de contatos como o principal motivador do espaço mediado, e os que evadiram, se justificaram pela

gestão do tempo; vii) que a avaliação geral do curso de formação dos Tutores foi positiva ( $>90 \%$ totalmente satisfatório); viii) que o aluno UAB está distante do proposto do público-alvo requerido pelo sistema $\mathrm{EaD}$, pelos critérios de motivação, disciplina e autonomia; e, ix) que a basilar missão do Tutor no sistema UAB é ensinar a autonomia ao aluno.

Ao final do percurso, os Tutores relataram que trabalharam, no espaço e tempo virtual e presencial, muitas vezes seguindo uma Teoria Intuitiva e de Sen- 
tidos (LANZ, 1979; Steiner, 1982), uma reflexão da leitura do mundo através das aprendizagens e narrativas dos alunos UAB/UFPE (FREIRE, 1983; FREIRE, 2006), e de uma observação da evolução do aprendizado individual pela construção coletiva (VIGOTSKY, 1989). O cumprimento exato e total das atribuições dos Tutores refletem em um sucesso no Processo de Tutoria, porém, o dia-a-dia na ciranda dentro habitat virtual (BRANDÃO, 1984), a cada contato Tutor-aluno, e a cada feedback institucional, transformaram o Tutor em um 'ser' que responde aos quesitos da Gestão Educacional: Educar o que? Para quem? Por que? Com isso, e tudo o que foi apresentado se pode afirmar que o Processo de Tutoria na Universidade Aberta do Brasil/Universidade Federal de Pernambuco é um sucesso, na superação, rumo a qualidade pré-requisitada pelo Sistema UAB.

\section{AUTO-AVALIAÇÃO}

A Coordenação de Tutoria UAB/UFPE de outubro de 2016 a julho de 2017 cumpriu as atribuições propostas pela Coordenação UAB/UFPE e pela Coordenação da Conecte/UFPE para o período referido. A coordenação coordenou o grupo de Tutores a Distância e o orientou na execução das atividades acadêmicas; teve disponibilidade para atuar de segunda a sábado no ambiente virtual e/ou presencial; dedicou, no mínimo, 2 (duas) horas diárias às atividades virtuais inerentes à função; dedicou também, no mínimo, presencialmente, na Sala da Coordenação do Curso ou da Tutoria, 2 (duas) horas contínuas semanais para reunião de planejamento didático com o grupo de Tutores a Distância e/ou com a coordenação pedagógica; desenvolveu as atividades docentes do componente curricular em oferta na modalidade a distância mediante o uso dos recursos e metodologia previstos no projeto académico do curso; participou dos encontros presenciais previstos no calendário/horário académico; apresentou ao coordenador de curso, ao final do componente curricular ofertado, relatório técnico final de desempenho dos estudantes e do desenvolvimento do componente curricular, relatórios dos encontros presenciais com as respectivas atas de presença dos estudantes e relatório de prestação de contas, caso seja disponibilizado ajuda de custo para realização dos encontros presenciais; e, desenvolveu, em colaboração com o coordenador de curso, a metodologia de avaliação do estudante.

\section{REFERÊNCIAS}

BILLOUET, P. Débattre: Pratiques scolaires et démarches éducatives. Paris: L’Harmattan, 2007.

BRANDÃO, C. R. Educação popular. São Paulo, SP: Brasiliense, 1984. 86 p.

FREIRE, A. M. A. Paulo Freire, uma história de vida. Villa das Letras, 2006.

FREIRE, P. Pedagogia do Oprimido. 13. ed. Rio de Janeiro: Paz e Terra, 1983. 218 p. 
LANZ, R. A pedagogia Waldorf: caminho para um ensino mais humano. 1979.

LIKERT, R. A technique for the measurement of attitudes. Archives of Psychology, v. 22, p. $140-155,1932$.

LIMA, M. L. DE F.; FONTES, A.; SANTANA, O. A. Monitoria Suplementa ou Complementa a Docência? Experiências na disciplina Introdução a Física. In: Encontro Anual da Biofísica 2017, 2017, Pernambuco. Blucher Biophysics Proceedings. São Paulo: Blucher, 2017. v. 1. p. 1-3. DOI: 10.5151/biofisica2017-001

PADILHA, M. A. S.; ZABALZA, M. A. Um Cenário de Integração de Tecnologias Digitais na Educação Superior: em Busca de uma Coreografia Didática Inovadora. Revista e-Curriculum (PUCSP), v. 14, p. 837-863, 2016.

SANTANA, O. A. Evasão nas Licenciaturas das Universidades Federais: entre a apetência e a competência. Educação (Santa Maria. Online), v. 41, p. 311-327, 2016a. Doi: 10.5902/1984644420199

SANTANA, O. A. Fragmentação dos movimentos sociais nas universidades da América Latina: 1990-2015. Universidade e Sociedade (Brasília), v. 57, p. 36-45, 2016b.

SANTANA, O. A. Resistência social na Caatinga árida: a narrativa de quem ficou no colapso ambiental. Desenvolvimento e Meio Ambiente (UFPR), v. 38, p. 419-438, 2016c. Doi: $10.5380 /$ dma.v38i0.43574

SANTANA, O. A.; PETROVA, Y. Ludicidade no Ensino da Normalidade em um Ambiente Florestal. Inter-ação (UFG. Online), v. 41, p. 525-544, 2016. Doi: 10.5216/ ia.v41i3.41502

SANTANA, O. A. Divórcios de Docentes de Universidades Federais Brasileiras. Cadernos de Estudos Sociais, v. 30, p. 61-77, 2015 a.

SANTANA, O. A. Teachers in Brazil: Social Mobility and Elements for Federalism Strategies. Creative Education, v. 06, p. 1629-1637, 2015b. Doi: 10.4236/ce.2015.615165

SANTANA, O. A.; SANTOS, N. K. B.; SILVA, M. M. DA; MORAIS, R. L. DE; ENCINAS, J. I. Árvores potenciais a danos urbanos: manejo através da tecnologia, educação e mobilização social. Revista Tecnologia e Sociedade, v. 11, p. 71-88, 2015. Doi: 10.3895/ rts.v11n23.2748

SANTANA, O. A. Ensino de ciências em Braille com histórias em quadrinhos roteirizados porcegos.LinhasCríticas(UnB),v.20,p.711-743,2014a.Doi:10.5965/15164896v20n432014711

SANTANA, O. A. Observação da Prática Docente: Um método para Licenciatura. 1. ed. Olinda: Livro Rápido, 2014b. v. 1. 50p. Doi: 10.12702/978-85-406-0942-6

SANTANA, O. A.; SILVA, T. P.; INÁCIO, E. DOS S. B.; OLIVEIRA, G. S. DE; SILVA, M. M. DA; Encinas, J. I. Integration of face-to-face and virtual classes improves test scores in Biology undergraduate courses on days with flooding in Brazil. Acta Scientiarum. Education (Print), v. 35, p. 117-123, 2013. Doi: 10.4025/actascieduc.v35i1.17219

Santana, O. A. Alunos egressos das licenciaturas em EAD (consórcios setentrionais e UAB: 2001-2012), sua empregabilidade e absorção pelo mercado. Revista Brasileira de Aprendizagem Aberta e a Distância, v. 12, p. 47-58, 2013. 
Santana, O. A. Docentes de pós-graduação: grupo de risco de doenças cardiovasculares. Acta Scientiarum. Education (Online), v. 33, p. 219-226, 2011. Doi: 10.4025/actascieduc.v33i2.13569

SANTANA, O. A.; Encinas, J. I.; PEIXOTO, L.R.T. Aluno como Ativo e Não Ativo em Ambiente Virtual de Aprendizagem em Uma Disciplina do Curso de Engenharia Florestal da Universidade de Brasília: 2005-2009. Revista de Ensino de Engenharia, v. 30, p. 43-48, 2011. Doi: 10.15552/2236-0158/abenge.v30n2p43-48

SANTANA, O. A.; PEIXOTO, L. R. T. Student perspectives about mobile learning initiatives at Open University of Brazil: the mobile phone issue. Acta Scientiarum. Education (Online), v. 32, p. 219-223, 2010. 10.4025/actascieduc.v32i2.11545

STEINER, R. Ciência oculta: Esboco de uma cosmovisao supra-sensorial(a). São Paulo, SP: Antroposofica, 1982. $232 \mathrm{p}$.

VIGOTSKY, L. S. A formação social da mente: o desenvolvimento dos processos psicológicos superiores. 3. ed. São Paulo: Martins Fontes, 1989. 168 p. 
